\title{
Strange Bodies. Dementia and Legacies of Colonialism in Fiona McFarlane's The Night Guest
}

Fiona McFarlane's novel The Night Guest (2010) tells the story of Ruth Field, an older woman living alone in an isolated house by the sea who believes that a mysterious tiger is visiting her home at night. Although the novel takes place in contemporary Australia, Ruth spent her childhood in colonial Fiji as the daughter of white missionaries, and her memories of this time begin increasingly to infiltrate her daily life. Ruth starts to become unwell and confused as the novel unfolds, and although the text never names dementia specifically, it is evident that she is experiencing many of the symptoms commonly associated with this cognitive disorder, for example, difficulties with memory and recall, losing her way in familiar places and becoming easily distracted. ${ }^{1}$ By keeping this condition latent in the text, however, McFarlane's novel asks us to reflect on the ways that as readers we might bring certain kinds of assumptions to bear on older bodies when we encounter them in texts. This incentive to reflect on our own biases is made compelling by the novel's depiction of two key relationships: the one between Ruth and the visiting tiger of the title, and also Ruth's connection to her live-in carer, Frida, whose presence is alternately comforting and abusive.

In this essay I will argue that The Night Guest is a novel particularly concerned with examining the ways in which bodies are 'read,' specifically how such a process might take place on the level of encounter. Sara Ahmed's work on strange encounters - with the terms 'reading' and 'encounter' crucial to her thoughtful and nuanced study of the ways that histories of colonialism intervene in contemporary discourse around the figure of the 'stranger' - informs my analysis here. I use Ahmed's work to theorise Ruth's relationships to two strangers that arrive in her life, Frida and the tiger, and argue that Ruth's apparent dementia is the textual device that makes visible the production of strangeness and familiarity that would normally remain tacit in these encounters. In particular, I consider how the novel's abnegation of the gap between colonial past and present (achieved through the merging of Ruth's childhood memories

1 For a useful overview of the symptoms commonly used to diagnose dementia see Hugo and Ganguli (2014).

Ә Open Access. (c) 2022 Emily Thew, published by De Gruyter. (c) BY-NC-ND This work is licensed under the Creative Commons Attribution-NonCommercial-NoDerivatives 4.0 International License. 
with her contemporary moment) suggests that violence is able to enter relationships when encounters are premised on the (colonial) desire to produce certain bodies as knowable.

\section{Encountering strangers}

In Strange Encounters: Embodied Others in Post-coloniality, Sara Ahmed sets out to critically examine the figure of the stranger across a number of political and theoretical contexts. She argues that the stranger, by being constituted as the outside of Western bodies, communities and nation-states, allows these entities to come into sovereign being. She further insists that attention be paid to the specific ways that notions of the stranger are mobilised at different times and in different places, pointing out that contemporary discourses of globalisation and multiculturalism produce and reproduce not only the figure of the stranger but the figure of the "stranger stranger" in order "to differentiate between some others and stranger others" (Ahmed 2000, 16). Such discourses rely, she explains, not only on the policing of borders but also on selective processes of welcoming.

Proceeding from this point, Ahmed's text examines the "strange encounters" through which the figure of the stranger is produced, "not as that which we fail to recognise, but as that which we have already recognised as 'a stranger"' (Ahmed 2000, 3). For Ahmed, this act of recognition takes place through a visual process of "reading the bodies of others," which means "seeing the difference between familiar and strange others as they are (re)presented to the subject" (21-24). Specifically, she is concerned with embodiment in this context and with the way that "in the gesture of recognising the one that we do not know, the one that is different from 'us,' we flesh out the beyond, and give it a face and form" (3). She argues that it is through this act of reading, this fleshing out of the other, that bodies then come to be produced as either strange or familiar.

Ahmed's task is to examine this process of "fleshing out" the stranger, the ways in which a subject seeks to recognise the body of another, "not only by rereading the body of this other who is faced, but by telling the difference between this other, and other others" $(2000,8)$. This process of reading the other becomes necessary because of the defining characteristic of the encounter as Ahmed theorises it: the element of "surprise" that is introduced when the encounter is "premised on the absence of a knowledge that would allow one to control the encounter, or to predict its outcome" (8). The surprising encounter contains within it the threatening possibility that "we may not be able to read the bodies of others," and this instigates the "fleshing out" process in which the 
strange body comes to be defined by "prior histories of encounter that violate and fix others in regimes of difference" (8).

Ahmed argues for the introduction of "particularity" when approaching these potentially pernicious histories of prior encounter that are called upon to make strangers "readable." Particularity in this sense involves a move outward to think of the "modes of encounter through which others are faced" (2000, 144). For this to happen, Ahmed (145) argues that the encounter needs to be located in time and space by asking "what are the conditions of possibility for us meeting here and now?" with this question allowing difference between bodies to be understood as "determined at the level of the encounter" by social processes that are not only at work in the present but that have been and will be active in other times and places. For Ahmed (145), there is an ethical possibility at stake in the idea that to focus on the particularity of an encounter in this way is also "to open the encounter up, to fail to grasp it." That is, surprise would be understood as sustaining rather than frustrating the relationship of the bodies involved. Her preferred terminology for this kind of opening up is the "close encounter," which she argues is "always a strange encounter, where something fails to be revealed" (181).

In this sense, her theory suggests that it is possible to take an interpretative approach to strangeness that is critical in nature, recognising strange bodies as produced (and seeking to contextualise this) while also remaining open to the possibility that these same bodies can still surprise. It seems to me that McFarlane's novel, focalised through Ruth's perspective, is similarly transparent about the ways Ruth's past experiences are brought to bear on the bodies of the figures she meets so that she might read them. However, the extent to which exposing the structures governing these encounters means opening up space for surprise varies. In the novel, this variation (the extent to which an encounter is able to remain surprising) is closed down when the conditions of possibility for the meetings are premised on legacies of colonialism, and it is opened up when space is made for the challenging experience of dementia to also include feelings of desire and joy. I will examine the differing modes of encounter that are shown in the novel through a close reading of Ruth's first meetings with the tiger and with Frida, and then I will show how Ruth's initial production of these two bodies shapes the remainder of the narrative.

\section{2 'Remembering' hospitality}

Ruth's initial meeting with the tiger takes place at the start of the novel and is narrated in the same style as the rest of the text (excluding a final coda): 
indirect discourse focalised through Ruth. The old woman is living alone and has not yet met Frida, who will soon move into her house, as we eventually discover, to gain closer control over Ruth's life and finances. Ruth's encounter with the tiger is distinctive in the text in that it is characterised by a sense of curiosity and joy that Ruth soon loses when she tells Frida about it, after which point the tiger begins to be purely a source of fear and anxiety for her. To put this first meeting in the context of Ahmed's theories in Strange Encounters, this textual moment works to expose the particular kinds of affective work that Ruth does to produce (and read) the strangeness of the tiger. However, at this point the novel also places an emphasis on Ruth's willingness to remain confused by, or fail to 'grasp,' the tiger's body, situating her encounter with the tiger in the context of an openness and curiosity that is interested, in Ahmed's terms, in the particularity of a body that nonetheless remains surprising.

Her first impressions of the tiger are auditory rather than visual; she does not see it (and will not until the close of the novel) but instead forms an impression of its activities from various distinctive sounds:

Something large was rubbing against Ruth's couch and television and, she suspected, the wheat-coloured recliner disguised as a wingback chair. Other sounds followed: the panting of a large animal; a vibrancy of breath that suggested enormity and intent; definite mammalian noises, definitely feline, as if her cats had grown in size and were sniffing for food with huge noses. But the sleeping cats were weighing down the sheets at the end of Ruth's bed, and this was something else.

(McFarlane 2014, 1-2)

After comparing the tiger's breathing and sniffing to that of her own cats, Ruth then goes on to liken the noises it makes to those of another tiger she once saw eating at a German zoo, which had "sounded just like this: loud and wet, with a low, guttural breathing hum punctuated by little cautionary yelps, as if it might roar at any moment except that it was occupied by food.” However, this visiting tiger differs in some important sense from that other, remembered tiger, in that as it busies itself with whatever "large bloody thing" it is intent on eating, the noise it makes is "empty and meatless." When Ruth calls her son Jeffrey in New Zealand, he wearily responds, "It's either a cat, or a dream," and, indeed, when she goes to investigate, the lounge room is "benign" despite "a vegetable smell in the long hallway, and an inland feel to the air" (2-3).

From the first moment of its arrival, then, the tiger presents an interpretative problem for the reader. Ruth makes sense of the tiger's body by recalling other bodies that remind her of this new strange one, each one replaced by another that does not quite fit. Domestic cat, echo of a long-ago zoo visit, "meatless" ghost and dream all at once, the tiger's body is both elusive and recognisable; it exceeds the known but holds out the promise of becoming knowable. Ruth brings 
the tiger into being by acknowledging the bodies that it is not, in order to grasp for the body-that-it-might-be. As such, the text offers us a tiger composed of fragments that come from and are rooted in Ruth's lived experience. In Ahmed's terms, Ruth tries to read the tiger's body by "telling the difference between this other, and other others," laying bare the mechanisms by which strange bodies come to be produced $(2000,8)$.

At the same time, Ruth's call to Jeffrey (and his dismissive response), alongside her recollection that on his last visit she had noticed a "watchful patience" in him, as well as "a tendency to purse his lips whenever she said something he considered unusual," simultaneously introduces into the text an element of doubt by giving us the first evidence that Ruth's family are beginning to be concerned about her mental wellbeing. The indirect discourse used by the narrator, and the fact that this implies Ruth's focalisation of events is subjective, gives us our first opportunity here to remain open (or not) both to Ruth as an experiencing subject and to the tiger as a body to be taken seriously. However, in Ahmed's terms, despite the fact that Ruth's reflections on her son's concerns introduce doubts about her cognizance, Ruth's response to the tiger provides an example of extending a 'remembering' rather than a 'forgetting' hospitality to the stranger's body.

Ahmed introduces the notion of a hospitality that 'remembers' through a critical reading of the figure of the arrivant, which Jacques Derrida first introduces in his book Aporias (1993) and which she argues prioritises a politics of 'forgetting.' For Derrida (33-34), arrivant can refer both to "the neutrality of that which arrives" and to "the singularity of who arrives" and this arrivant "surprises the host - who is not yet a host or an inviting power - enough to call into question, to the point of annihilating or rendering indeterminate, all the distinctive signs of a prior identity." For Ahmed (2000, 151):

Such a hospitality is based on the forgetting of the names that are used, however inadequately, to locate subjects in a topography of time and place. In contrast, what is required is a hospitality that remembers the encounters that are already implicated in such names (including the name of "the stranger"), and how they affect the movement and "arrival" of others, in a way which opens out the possibility of these names being moved from. This hospitality, premised on the surprise of an opening or gift, would begin by admitting to how the assimilation of others, and the differentiation between others, might already affect who or what may arrive, then or now, here or there.

In Ruth's encounter with the tiger, we find an example of what this kind of 'remembering' hospitality might look like in practice. Ruth remembers the 'other' bodies (cat, zoo tiger, uncanny ghost) that she has already assimilated into categories of knowledge and then differentiates between these in order to make her visiting tiger knowable (that is to say, in order to allow the tiger to arrive). McFarlane makes visible this process of remembering and the production of 
strangeness that accompanies it. As Ahmed might put it, she 'admits' that such a process is operative in the encounter between Ruth and tiger. At the same time, however, the novel holds open the possibility that Ruth's encounter with the tiger might be premised on "the surprise of an opening or gift" (151). This is achieved primarily by figuring Ruth's relationship to the tiger in terms of desire. When Ruth ventures out into her hallway to try to lay eyes on the tiger, who is nowhere to be found, she is aware of

Another sensation, a new one, to which she attended with greater care: a sense of extravagant consequence. Something important, Ruth felt, was happening to her, and she couldn't be sure what it was: the tiger, or the feeling of importance. [. . . ] She felt something coming to meet her - something large, and not a real thing of course, she wasn't that far gone - but a shape, or anyway a temperature. It produced a funny bubble in her chest.

(McFarlane 2014, 4)

The text makes it clear that the tiger has an important meaning for Ruth, the sense of "extravagant consequence" that she understands in terms of an encounter ("something coming to meet her") that is also a movement forward or an opening out. The feeling reminds Ruth "of something vital - not of youth exactly, but of the urgency of youth," and she is "reluctant to give it up" (6). This attachment performs important work in the text by positioning Ruth in a dynamic relation to the tiger, one that is desiring and open to surprise.

Therefore, while Ruth does try to read the tiger's body by bringing it into dialogue with other bodies, she also does not react to its strangeness by using these "prior histories of encounter" to close down the animal's meaning. Instead, the encounter with the tiger proceeds on Ruth's part with a kind of openness to missing his body. In this case, the desire - the "extravagant consequence" she feels in relation to his presence - is not fixed to a definite subject but is instead experienced affectively as a shape, a temperature, a sense of largeness. This openness extends even further to a willingness to entertain the notion of her own subjectivity being subsumed by the tiger's. She is "delighted" to imagine newspaper headlines reading "'Australian Woman Eaten by Tiger in Own House,"” or, "more likely, 'Tiger Puts Pensioner on the Menu'" (McFarlane 2014, 4). As such, Ruth's encounter with the tiger can be understood as one of Ahmed's "close encounters" in the sense that the material and psychical slipperiness of the tiger's body, the fact that it does not reveal itself in any fixed way, enriches and opens up the relationship between their two bodies, even to the extent that her desire to consume is reversed.

By situating the unknowability of the tiger in terms of desire and excitement, then, the text shows that the openness at work in Ruth's encounter with the tiger is not simply an ethical practice of responding to otherness; it also holds out the possibility that there might be joy or pleasure to be found in such 
a "close" encounter with strangeness. I would argue that on a larger textual level, McFarlane's novel positions the pleasure and joy to be found in surprise as one of the potential rewards awaiting a reader both hospitable to strangeness within a text and attentive to their own implication in the reading, or production of, that strangeness. Crucially, however, such rewards are dependent on a reader remaining open to Ruth's narrative perspective and resisting a focus which would prioritise establishing the 'reality' of her experiences over and above her agency as a desiring subject. Such an approach is complicated, however, by the second important encounter in the novel: that between Ruth and Frida. Here, while the 'remembering' hospitality that Ruth enacts still usefully exposes the ways that Frida is produced as a visiting stranger, the prior encounters that Ruth engages with in order to make sense of Frida's arrival are anchored in her colonial childhood and depend upon a process of racialisation that 'fixes' Frida's identity.

\section{3 'Knowing' the stranger}

Frida arrives the morning after Ruth hears the tiger, telling Ruth she has been sent by the government to be her carer because a spot has opened up on a state programme. Just as with the tiger, the element of 'surprise' at work in Frida's arrival introduces a stranger whose presence is threatening because it is "premised on the absence of a knowledge that would allow one to control the encounter, or to predict its outcome." This threat triggers what Ahmed calls the "fleshing out" process, whereby Ruth seeks to read the stranger's body by drawing on prior histories of encounter. However, in this incidence the histories that Ruth engages with to understand her encounter with Frida are specifically those of her missionary childhood in Fiji, and as such they directly draw on colonial dynamics that work (and indeed are designed to) "fix others in regimes of difference" (Ahmed 2000, 8).

This is made explicit in the text in that Ruth's affective response to her meeting with Frida is directly grounded in a racialisation of her body. The narrator reports that Frida's "breadth and the warmth of her skin and the dark sheen of her obviously straightened hair looked Fijian to Ruth"2 and that this is enough to make her feel "optimistic about the encounter" (McFarlane 2014, 8). Just as with the tiger, the text clearly signals that Ruth's attempts to read and

2 Ruth's racialisation of Frida has her hair as its main focus, with Ruth continually noticing the care Frida takes over it and the way it changes colour and style. 
define Frida's body (in this racialised sense) are to be understood as producing Frida's body, rather than as factual reportage of Frida's physical appearance. This is primarily an effect of the indirect discourse used in the novel, focalised through Ruth. The text informs the reader not that Frida is Fijian but that she "looks" Fijian, and, importantly, that she looks this way "to Ruth." As such, the possibility of Frida's being Fijian is both opened up and obscured; the authority of third-person narration leads us to assume that the idea that she looks Fijian is factual, while the insistence that this view is focal (Ruth's interior voice) reveals that it is in fact perspectival. In this sense, the text shows how supposedly visible categories of strange(r)ness (in this case the ways that bodies are racialised) can in fact be produced discursively in order to "violate and fix others in regimes of difference" (Ahmed 2000, 8). The nature of Ruth and Frida's relationship for the rest of the novel is dictated by the way this first encounter 'fixes' Frida in Ruth's mind; in contrast to her surprising meeting with the tiger, this relationship is characterised by a narrow focus on Frida's supposed Fijian identity that leaves no room for such surprise, with violent consequences.

I believe that this initial fixing of Frida's identity goes some way to answering one of the key questions in The Night Guest: How does Frida manage to insert herself into Ruth's life so easily and, in doing so, cause so much damage? As the novel progresses, Ruth becomes increasingly dependent on Frida, who moves (uninvited) into Ruth's home, encourages Ruth to sell her car (without which she is isolated in her remote house) and begins to make requests for money; all of this happens without interference or protest from family and friends and without the reader being sure whether Ruth has in fact invited or agreed to them. It seems to me that these events are enabled because Ruth's initial reading of Frida's body is taken up by her son Jeffrey in a way that assumes that to racialise Frida is to render her knowable - or, in Ahmed's terms, to produce her as familiar. When Jeffrey calls to check on Ruth moments after Frida's arrival, he insists on speaking with her and after a brief conversation seems satisfied that all is well. Ruth tries to override her uncertainty about the situation by telling him that Frida is Fijian, "mainly for her own reassurance." His reply is brief, and dismissive: "There you are, some familiarity” (McFarlane 2014, 12). If Ruth's reading of Frida, and her communication of this to Jeffrey emerges in part from a need to make Frida readable, then Jeffrey's unquestioningly positive response vindicates Ruth's decision to fix Frida's identity in this way. Not only this, he chooses to refer to Frida specifically as an opportunity for "familiarity" in a speech act that produces her as familiar rather than strange, while also hinting at the legacy of colonial appropriation of native peoples for labour. That is, Jeffrey assumes in his reaction to Ruth on the telephone that the identity 'Fijian' is knowable to the point that 'Fijian' means 'familiar.' 
Crucially, McFarlane's novel suggests here (and will continue to do so throughout the text) that the conditions of possibility for Frida entering Ruth's life in the way she does are dependent on legacies of colonialism that understand the 'stranger' as, in Ahmed's words, "knowable, seeable, and hence be-able" (Ahmed 2000, 133). The conversation between Ruth and Jeffrey works as a kind of nodal point in the text in that it presents one of the first moments at which the reader is able to see, if not understand, some of the lines of convergence whereby the strange(r) is both produced and read as familiar. Furthermore, the movements of desire at work in the tripartite encounter that takes place when Ruth tells Jeffrey about Frida's arrival can be understood as colonial in the sense that they flow backward (nostalgically) via the act of racialisation towards a reduction in meaning, a closing down of the possibilities Frida's body has to surprise. Therefore, although Ruth's encounter with Frida is the inverse of the open one that takes place between Ruth and the tiger, it similarly exposes the workings of this meeting, demanding that attention be paid to the ways that strangers are read and produced.

Furthermore, if we choose to see Ruth's identification of Frida as Fijian as dependent on another condition of possibility - Ruth's dementia - then we can also begin to notice the way that dementia's fusing of past and present experience becomes the means of exposing the workings of the encounters that take place in the text. If recognising the stranger involves recognising them as familiar in their strangeness (and thus distinct from and generative of the stranger stranger), it also relies on the fact that the categories of recognition being used to produce these different kinds of stranger are working for the host (the one who names the stranger) in the way that they are supposed to, or at least that the host has some kind of agency over these categories. In The Night Guest, then, Ruth's dementia becomes a key means of exploring what happens when such processes fail and of asking us to consider our own relationship to these ways of 'fixing' difference.

\section{Dementia and narrative voice}

Ruth's illness is first introduced in small and unremarkable ways, perhaps signalling only a benign self-neglect. For example, when Frida arrives for the first time, Ruth is having pumpkin seeds for breakfast and is accustomed to dressing in her sons' old T-shirts, although later she is horrified to realise that she has forgotten to wash her hair - perhaps for weeks. However, as Frida becomes more omnipresent, Ruth grows confused and begins to doubt herself. This comes to an 
initial climax when Ruth discovers Frida is staying in the house in one of the spare bedrooms. When confronted, Frida insists that she and Ruth have discussed the arrangement, and although Ruth begins to argue ("that isn't true Frida, what you're saying to me now, it's not true. I'd remember"), she nevertheless experiences "a feeling of unravelling, all the same; an unwound thread" (McFarlane 2014, 8). Ruth's health then begins to deteriorate after a physically abusive incident during which Frida locks her out of the house. After this point her confusion increases and although her narrative voice is still strong and lively, in conversation with other characters her responses are erratic and often childlike. Throughout this series of events, the tiger remains a constant presence, mainly making himself known to Ruth through changes in the night-time atmosphere of the house.

In part, the introduction of dementia into the text is straightforwardly disruptive, acting as a device for McFarlane's text to explore what it might mean for the 'proper' recognition of strangers and strangeness to stop working or go wrong. However, although the novel is clearly attentive to and interested in the potential that the act of recognising (and so producing) strangeness has to break down, or glitch, in interesting and productive ways, to see dementia as the device that illuminates or gives order to this idea in the text would be to miss the truth of its emergence. The question the text asks is not whether Ruth does or does not have dementia (whether what she sees or experiences is or is not 'real' in any sense); instead, the novel asks us to focus on our own drive to establish the 'realness' of events and the ways that doing this might at the very least be unpleasurable for Ruth, if not actively harmful, because it denies her any agency. In raising the possibility but not determining that Ruth has dementia, the text puts us in a position where we must continuously pay attention to and become aware of the limits of our own generosity - to the ways, that is, that we might want to 'fix' Ruth in order to make sense of her difference.

Primarily, this means that we need to reckon with the extent to which, in deciding whether to make space for Ruth and her tiger or not, we are allied with Frida. For a large part of the novel, Frida's manipulations of Ruth are subtle, and the indirect discourse produces an effect whereby the reader is both within and outside Ruth's consciousness; we see the world through her eyes but are able to maintain a critical distance from her narrative voice. As such, although the text cultivates suspicion towards Frida and alertness to her potential motives for exploiting Ruth (for example, she talks to Ruth at length about money troubles caused by her unreliable 'brother' George, who is later revealed to be her husband), definite proof of Frida's ill intentions largely remains absent from the text. However, there comes a point of rupture in the novel when Frida flat out refutes Ruth's (correct) assertion that Suva is the capital of Fiji, telling her "'you don't 
know [. . .] you only think you do"' (McFarlane 2014, 173). At this point Frida's gaslighting of Ruth becomes violently explicit, directing our attention to the ways that we may have made similar judgements in relation to Ruth's narrative perspective. By explaining to Ruth that she does not know, she only 'thinks' she knows, Frida's words draw attention to the threat that lurks within the pages of this text; namely, reading strategies that aim to identify and fix certain kinds of knowledge within both texts and bodies, enact violence on these texts and these bodies. Who are you, we might want to demand of Frida, to decide what is and is not true? Who are you, the text reminds us, to do the same? ${ }^{3}$ The main locus of these questions is of course the tiger, and in the final part of the novel, Frida's project is to undo the productive and essentially open set of relations Ruth holds towards him in order to claim full ownership of her imaginative world.

\section{The "stranger stranger"}

When Ruth tells Frida that she has heard a tiger visiting the house at night, she is at first met with "jovial scorn" and told that there are "no tigers in Australia" (McFarlane 2014, 144-145). Soon, however, it is Frida who has "settled into the possibility of the tiger," which she insists is probably "man-eating” or, indeed, "woman-eating" (145). This turnaround unsettles Ruth. Faced with this new version of the tiger, which is frightening not because he might be interested in eating her (she has of course entertained and enjoyed that possibility before) but because he is Frida's version - she feels compelled to refute his existence, again and again. Indeed, this happens four times on one page alone (144). Despite Ruth's insistence that she must have made a mistake, Frida spends the night on the sofa in the living room. Although Ruth is partly annoyed by the idea that Frida is teasing her, she sees "without wanting to, evidence of Frida's seriousness: her crushed hair, the displaced sofa cushions, the cups of tea" (153). Frida's interest in the tiger then culminates in two violent incidents where she supposedly confronts him while Ruth remains locked in her bedroom. After the first of these, Frida is left with three scratches on her arm, and, although she insists she has "scared him right off," she commences building "tiger traps" around the outside of the house, the largest being a big hole halfway down the dune below Ruth's garden. The second time Frida fights the tiger, she tells Ruth

3 In her book Forget Memory, Anne Davis Basting $(2009,27)$ examines a number of studies that suggest an amount of cognitive loss may in fact "be triggered by the way people treat you." 
he is dead. She has killed him by cutting open his stomach and slitting his throat, dumping his body out to sea in a wheelbarrow.

Frida's decision to take the possibility of the tiger seriously completely changes his meaning for Ruth, because Frida now gets to decide who and what he is. Ruth realises "the tiger was Frida's now; and not just this tiger, but the entire species" (McFarlane 2014, 163). 'Frida's tiger' is generic rather than individual, standing in for all other tigers rather than existing as the singular and complex creaturely (non)being that Ruth met in their first encounter. I argued earlier in this essay that her reading of his body against other, different bodies constituted an example of the kind of 'remembering' hospitality that Ahmed suggests would be honest about the ways that a host subject is always already implicated in the recognition, or non-recognition, of whichever visitor might arrive. Instead, Frida embarks on a project of reducing the meaning of the tiger; she cements her own status as a safe, or knowable, stranger, by actively producing the tiger as the "stranger stranger," the one who must be expelled in order for her to be "taken in" (Ahmed 2000, 133).

While Frida achieves this expulsion in a staged sense through her battles with the tiger, she also seeks to fix the tiger's meaning more discursively by drawing upon aspects of Fijian colonial history. In presenting this, the text once again suggests that when colonialism is one of the conditions of possibility for encounters between bodies, these bodies become restricted in their capacity to mean. In this specific case Frida works to associate the tiger with India, which in the light of Ruth's racialisation of Frida, calls to mind the historical conflict in Fiji between so-called indigenous Fijians and the Indo-Fijian population originally brought to the island as indentured labourers. In foregrounding Ruth's affection for Fiji and its inhabitants, McFarlane's text seems to be drawing on histories of Fiji's colonisation that stress the occupying British officials' regard for the Fijians as a supposedly "exemplary colonial people" (Denoon et al. 2000, 323). Along these lines, Frida's opposition of herself (as 'Fijian') to the tiger draws on a prejudicial dynamic whereby she is the "exemplary" stranger that produces the tiger as the 'stranger stranger.'

For example, immediately when Ruth mentions the tiger, Frida draws a connection between the animal's arrival and Ruth's childhood in Fiji, which she calls "that jungle you grew up in." Ruth protests ("I didn't grow up in a jungle. [. . .] And there are no tigers in Fiji”), instead insisting that tigers are accustomed to cold weather and "live in India and China. Maybe Russia." In response, Frida cryptically asserts that there are "Indians in Fiji [. . . ] everyone knows that, from the news.” Despite Ruth's dismissal of this - "just because there are Indians in Fiji doesn't mean there are Indian tigers. I thought everyone knew that"(McFarlane 2014, 144) - Frida and Ruth's conversation draws a link between tigers, India and Fiji. Specifically, Frida connects India and Fiji in the context of "the news," 
that is, the recurrent coups that have dogged Fijian politics since 1987 and have been presented in the media as the result of ongoing conflict between 'indigenous' Fijians and the Indo-Fijian population (Tran 2017). Frida is also insistent on characterising the tiger as a "man-eater” (“you're lucky you haven’t been gobbled up in your bed"; “Tiger on the loose, chances are it's a man-eater”) and again perseveres in suggesting this aspect of the tiger's nature is related to its particular Indianness. She tells Ruth, with apparent relish, "I saw a TV show once [... .] yeah, a documentary about man-eating tigers in India. You know what they say, once a tiger gets a taste of human flesh, that's all it wants to eat” (McFarlane 2014, 147).

In exorcising the tiger from Ruth's house, Frida successfully cements herself as protector, and after taking Ruth to the bank and getting her to sign over a large cheque, Frida prepares to leave with her 'brother' George. As it turns out, George has absconded with Ruth's money, and the novel ends with a strange coda that relates the fates of Ruth and Frida: both are dead, Ruth outside in the garden, and Frida it seems by suicide, her body found in the sea.

\section{The affect of resolution}

The coda also uses indirect discourse, but this time it is focalised through the voice of Ellen Gibson, a neighbour of Ruth's who has agreed to adopt her two cats. Ellen visits the house, and through a discussion with Ruth's sons we learn about the deaths of the two women, as well as a little about Frida's origins (she is English with Maori heritage and worked as a cleaner in a nearby nursing home). It is something of a flat conclusion to the novel, and after many pages of such interpretative complexity it feels strange to have the mysteries of the text resolved. It seems to me, however, that this is in fact the project of the coda; to show the removal of pleasure that takes place when everything becomes readable and to drive home the emptiness that comes with such a tidy resolution of the plot - a resolution bought at the expense of the lives of Ruth and Frida. The coda allows us to experience the loss of Ruth and her rich narrative perspective affectively, and it is this closing drabness that points to the text's continuing investment in the unreadable, the excess that allows for the preservation of surprise.

This is further demonstrated by the resurrection of the tiger in the final chapter before the coda. Ruth, carefully placed outside in the garden by Frida (an act of tenderness the purpose of which remains uncertain), sees him walking towards her, "the colour of the gone sun" (McFarlane 2014, 266). In writing this moment between Ruth and the tiger, an encounter that clearly tells the story of Ruth's 
death, the novel opens up the tiger's body to new kinds of meaning in introducing a spiritual dimension to his presence, allowing him to remain a knot of interpretative difficulty. In this sense, then, the text maintains a useful tension that stages the pleasure of the close encounter, "where something fails to be revealed," at the same time as owning up to the ways that prior histories of encounter might be used as tools to "fix others in regimes of difference" (Ahmed 2000,181, 8). If dementia is one of the narrative devices that works to make these prior histories of encounter visible, it is also the tool that allows us as readers to experience a narrative perspective that, once taken from us in the coda, we can recognise as a voice that has allowed for surprise and complexity. Recognising this, however, brings little in the way of joy - the cost (Ruth and Frida's deaths) is too great. As such, the text avoids romanticising the experience of dementia or reducing it to a cultural formation, while also asking us to consider what 'care' might actually mean, and how it might be unevenly distributed between different bodies.

\section{References}

Ahmed, Sara. Strange Encounters: Embodied Others in Post-coloniality. London: Routledge, 2000.

Basting, Anne Davis. Forget Memory: Creating Better Lives for People with Dementia.

Baltimore, MD: Johns Hopkins UP, 2009.

Denoon, Donald, Philippa Mein Smith and Marivic Wyndham. A History of Australia, New Zealand, and the Pacific. Oxford: Blackwell, 2000.

Derrida, Jacques. Aporias. Trans. Thomas Dutoit. Stanford, CA: Stanford UP, 1993.

Hugo, Julie, and Mary Ganguli. "Dementia and Cognitive Impairment: Epidemiology, Diagnosis, and Treatment." Clinics in Geriatric Medicine, 30.3 (2014): 421-42.

McFarlane, Fiona. The Night Guest. London: Sceptre, 2014.

Tran, Mark. "Fiji's History of Coups." Guardian, 5 December 2006. https://www.theguardian. com/world/2006/dec/05/fiji.travel1 (22 March 2017). 